\title{
Model Probabilistik Fuzzy Goal Programming Berdistribusi Pareto dengan Urutan Prioritas pada Permasalahan Produksi Kue
}

\author{
Eka Susanti \\ Jurusan Matematika Fakultas MIPA Universitas Sriwijaya \\ Email: eka susanti@mipa.unsri.ac.id \\ Oki Dwipurwani \\ Jurusan Matematika Fakultas MIPA Universitas Sriwijaya \\ Email: Okidwip@unsri.ac.id \\ Robinson Sitepu \\ Jurusan Matematika Fakultas MIPA Universitas Sriwijaya \\ Email: robinson.sitepu@ rocketmail.com \\ Wulandari \\ Jurusan Matematika Fakultas MIPA Universitas Sriwijaya \\ Liani Natasia \\ Jurusan Matematika Fakultas MIPA Universitas Sriwijaya
}

\begin{abstract}
Yulis's home industry is one of the Small and Medium Bussiness (UKM) on Palembang city. Yulis's home industry produces bolu kukus, kue lapis, kue pare, kumbu kacang, srikaya, and wajik. Most of cakes that will be produced by Yuli is still based on the cake sale on the last day, so that the profit is still not optimal condition. This research aims to create preemptive priority additive approach to Fuzzy Goal Programming Probabilistic (PFGP) model with Pareto distribution for maximize profits, minimize the production of perishable cake, and maximize best sellers cake. The results are obtained maximum profit is Rp. 8.488 .569 on a week, the amount of perishable cake is 1,295 pieces on a week, and optimal production for best seller cake as much as 8,489 pieces on a week.
\end{abstract}

Keywords : PFGP, Pareto Distribution, Preemptive Priority.

\section{Pendahuluan}

Salah satu bidang UKM dalam negeri yang menunjukkan perkembangan cukup pesat ialah bidang industri makanan (bolomba dkk, 2016). Usaha produksi kue Yuli adalah salah satu UKM yang di Palembang. Usaha Yuli memproduksi berbagai macam produk makanan, seperti bolu kukus, harum manis, kue lapis, kue pare, kumbu kacang, srikaya, dan wajik. Aktivitas produksi pada industri ini masih menggunakan perkiraan. Perencanaan 
produksi yang tepat sangat dibutuhkan oleh industri ini untuk dapat mencapai tujuan-tujuan yang diinginkan. Perencanaan produksi dapat menggunakan pendekatan matematika. Model Goal Programming (GP) dapat digunakan dalam kegiatan perencanaan produksi. Model Linier GP adalah bentuk khusus dari Linier Programming (LP), pada GP terdapat variabel deviasional dan beberapa tujuan yang akan dicapai secara simultan. Model GP merupakan salah satu teknik yang dapat digunakan dalam pengambilan keputusan pada permasalahan yang melibatkan lebih dari satu tujuan dengan penyelesaian secara serentak (Barik, 2015). Menurut Elikson D dalam Hartini dkk (2014), tujuan-tujuan tersebut dapat saling berkaitan dan juga saling bertentangan.

Harga bahan baku yang tidak tetap mengakibatkan nilai variabel dan tujuan yang diinginkan tidak dapat didefinisikan dengan pasti, sehingga untuk mengatasi kondisi ketidakpastian dilakukan pendekatan fuzzy. Model GP dengan bilangan fuzzy dikenal dengan model Fuzzy Goal Programming (FGP). Adanya nilai dari beberapa parameter pada model FGP yang tidak diketahui membuat persoalan FGP berada dibawah pemrograman stokastik. Model FGP yang terdiri dari beberapa variabel acak dengan distribusi probabilitas yang diketahui disebut sebagai model Probabilistik Fuzzy Goal Programming (PFGP).

Kue yang diproduksi oleh Yuli mempunyai batas waktu ketahanan tertentu untuk dapat dikonsumsi. Dalam matematika, analisa statistik yang membahas tentang daya tahan hidup suatu benda atau individu dalam keadaan operasional tertentu adalah analisa data uji hidup. Salah satu distribusi yang ada dalam analisa data uji hidup adalah distribusi Pareto. Penerapan analisa ini pada bidang produksi berkaitan dengan pemodelan tentang ketahanan hidup benda-benda produksi yang seringkali disebut keandalan atau reliabilitas (Saifudin, 2006). Model PFGP berdistribusi Pareto untuk permasalahan produksi industri kue Yuli dapat diterapkan.

\section{Metode}

Berikut diberikan Langkah-langkah penyelesaian permasalahan optimal produksi pada usaha kue Yuli:

1. Pengumpulan data sekunder, yaitu data jenis dan harga jual per potong (per satuan) setiap kue, jumlah produksi, bahan baku pembuatan kue, persediaan bahan baku, penjualan setiap kue dan biaya produksi.

2. Mendefinisikan variabel dan parameter keputusan yang digunakan, dengan variabel $x_{1}, x_{2}, x_{3}, x_{4}, x_{5}, x_{6}$ masing-masing secara berurutan yaitu bolu kukus, kue lapis, kue pare, kumbu kacang, srikaya dan wajik sedangkan jumlah bahan baku berupa gula merah, gula putih, kacang hijau kupas, kacang merah, kelapa, ketan, santan, telur, tapioka, tepung ketan, dan tepung terigu sebagai parameter. 
3. Membentuk model PFGP yang diperkenalkan oleh Barik (2015).

4. Mentransformasikan model PFGP berdistribusi Pareto dengan urutan prioritas memaksimalkan keuntungan, meminimalkan produksi kue yang cepat basi, dan memaksimalkan penjualan kue yang banyak laku ke bentuk deterministik.

5. Menyelesaikan model PFGP berdistribusi Pareto yang diperoleh pada Langkah 4 menggunakan alat bantu software Lingo 17.0.

6. Interpretasi hasil.

7. Kesimpulan.

\section{Hasil Dan Pembahasan}

Berikut diberikan data penggunaan bahan baku selama satu minggu.

Tabel 1. Penggunaan dan Persediaan Bahan Baku

\begin{tabular}{|c|c|c|c|c|c|c|c|c|}
\hline \multirow{3}{*}{ No. } & \multirow{3}{*}{$\begin{array}{c}\text { Jenis Bahan } \\
\text { Baku } \\
\text { Produksi }\end{array}$} & \multicolumn{6}{|c|}{ Jumlah Bahan Tiap Kue (Kg) } & \multirow{3}{*}{$\begin{array}{c}\text { Perkiraan } \\
\text { Persediaan } \\
\text { Bahan } \\
\text { Baku } \\
\text { mingguan } \\
(\mathrm{Kg}) \\
\end{array}$} \\
\hline & & $\begin{array}{l}\text { Bolu } \\
\text { Kukus }\end{array}$ & $\begin{array}{l}\text { Kue } \\
\text { Lapis }\end{array}$ & $\begin{array}{l}\text { Kue } \\
\text { Pare }\end{array}$ & $\begin{array}{l}\text { Kumbu } \\
\text { Kacang }\end{array}$ & Srikaya & Wajik & \\
\hline & & $\left(x_{1}\right)$ & $\left(x_{2}\right)$ & $\left(x_{3}\right)$ & $\left(x_{4}\right)$ & $\left(x_{5}\right)$ & $\left(x_{6}\right)$ & \\
\hline 1. & Gula Merah & - & - & - & - & - & 0,00267 & 6,2 \\
\hline 2. & Gula Putih & 0,01 & 0,01 & 0,0144 & 0,007 & 0,0167 & 0,0067 & 134,5 \\
\hline 3. & $\begin{array}{l}\text { Kacang } \\
\text { Hijau Kupas }\end{array}$ & - & - & 0,0144 & - & - & - & 15,4 \\
\hline 4. & $\begin{array}{l}\text { Kacang } \\
\text { Merah }\end{array}$ & - & - & - & 0,013 & - & - & 35,5 \\
\hline 5. & Kelapa & - & - & - & 0,008 & - & - & 21 \\
\hline 6. & Ketan & - & - & - & - & - & 0,014 & 35,7 \\
\hline 7. & Santan & - & 0,0245 & - & - & 0,0167 & 0,014 & 131,5 \\
\hline 8. & Telur & 0,008 & - & - & - & 0,04 & - & 48,9 \\
\hline 9 & Tapioka & - & 0,01 & - & - & - & - & 43 \\
\hline 10. & $\begin{array}{l}\text { Tepung } \\
\text { Ketan }\end{array}$ & - & - & 0,01 & - & - & - & 11,9 \\
\hline 11. & $\begin{array}{l}\text { Tepung } \\
\text { Terigu }\end{array}$ & 0,005 & - & - & - & - & - & 20,4 \\
\hline
\end{tabular}

Sumber : Industri kue rumah Yuli, Maret 2018

Berdasarkan data-data yang telah diperoleh, persoalan produksi pada industri kue Yuli dapat dibentuk kedalam model PFGP sebagai berikut:

Tentukan $X=\left\{x_{1}, x_{2}, x_{3}, x_{4}, x_{5} x_{6}\right\}$ untuk mengoptimalkan fuzzy goals berikut:

$f_{1}(x)=980 x_{1}+787 x_{2}+749 x_{3}+971 x_{4}+1.023 x_{5}+813 x_{6} \geqslant 8.488 .570$ (Goal

Keuntungan) 
$f_{2}(x)=x_{3}+x_{5} \preccurlyeq 1.295$ (Goal Jumlah Produksi kue cepat basi)

$f_{3}(x)=x_{1}+x_{2}+x_{4} \geqslant 8.736$ (Goal Jumlah kue banyak laku) dengan kendala

$$
\begin{aligned}
& \operatorname{Pr}\left(0,00267 x_{6} \leq b_{1}\right) \geq 1-\gamma_{1} \\
& \operatorname{Pr}\left(0,01 x_{1}+0,01 x_{2}+0,0144 x_{3}+0,007 x_{4}+0,0167 x_{5}+0,0067 x_{6} \leq b_{2}\right) \geq 1-\gamma_{2} \\
& \operatorname{Pr}\left(0,0144 x_{3} \leq b_{3}\right) \geq 1-\gamma_{3} \\
& \operatorname{Pr}\left(0,013 x_{4} \leq b_{4}\right) \geq 1-\gamma_{4} \\
& \operatorname{Pr}\left(0,008 x_{4} \leq b_{5}\right) \geq 1-\gamma_{5} \\
& \operatorname{Pr}\left(0,014 x_{6} \leq b_{6}\right) \geq 1-\gamma_{6} \\
& \operatorname{Pr}\left(0,0245 x_{2}+0,0167 x_{5}+0,014 x_{6} \leq b_{7}\right) \geq 1-\gamma_{7} \\
& \operatorname{Pr}\left(0,008 x_{1}+0,04 x_{5} \leq b_{8}\right) \geq 1-\gamma_{8} \\
& \operatorname{Pr}\left(0,01 x_{2} \leq b_{9}\right) \geq 1-\gamma_{9} \\
& \operatorname{Pr}\left(0,01 x_{3} \leq b_{10}\right) \geq 1-\gamma_{10} \\
& \operatorname{Pr}\left(0,005 x_{1} \leq b_{11}\right) \geq 1-\gamma_{11} \\
& x_{1}, x_{2}, x_{3}, x_{4}, x_{5}, x_{6} \geq 0
\end{aligned}
$$

Fungsi keanggotaan goal keuntungan

$P_{1} \mu_{1}\left(f_{1}(X)\right)=\left\{\frac{980 x_{1}+787 x_{2}+749 x_{3}+971 x_{4}+1.023 x_{5}+813 x_{6}-2.790 .585}{5.697 .985}\right.$,

bernilai 1 jika $980 x_{1}+787 x_{2}+749 x_{3}+971 x_{4}+1.023 x_{5}+813 x_{6} \geq 8.488 .570$

bernilai 0 jika $980 x_{1}+787 x_{2}+749 x_{3}+971 x_{4}+1.023 x_{5}+813 x_{6} \leq 2.790 .585$

Fungsi keanggotan goal jumlah kue cepat basi adalah:

$P_{2} \mu_{2}\left(f_{2}(X)\right)=\left\{\begin{array}{cl}1, & \text { jika } x_{3}+x_{5} \leq 1.295 \\ \frac{1.785-\left(x_{3}+x_{5}\right)}{490}, & \text { jika } 1.295 \leq x_{3}+x_{5} \leq 1.785 \\ 0, & \text { jika } x_{3}+x_{5} \geq 1.785\end{array}\right.$

Fungsi keanggotaan goal jumlah kue banyak laku 


$$
P_{3} \mu_{3}\left(f_{3}(X)\right)=\left\{\begin{array}{cl}
1, & \text { jika } x_{1}+x_{2}+x_{4} \geq 8.736 \\
\frac{x_{1}+x_{2}+x_{4}-2.660}{6.076}, & \text { jika } 2.660 \leq x_{1}+x_{2}+x_{4} \leq 8.736 \\
0, & \text { jika } x_{1}+x_{2}+x_{4} \leq 2.660
\end{array}\right.
$$

Bentuk deterministik model PFGP berdistribusi Pareto (1) dengan tiga urutan prioritas dirumuskan sebagai berikut.

Maksimum

dengan kendala

$$
D(\mu)=P_{1} \mu_{1}^{*}\left(f_{1}(X)\right)+P_{2} \mu_{2}{ }^{*}\left(f_{2}(X)\right)+P_{3} \mu_{3}^{*}\left(f_{3}(X)\right)
$$

$$
\begin{aligned}
& P_{1} \mu_{1}\left(f_{1}(X)\right)=\frac{980 x_{1}+787 x_{2}+749 x_{3}+971 x_{4}+1.023 x_{5}+813 x_{6}-2.790 .585}{5.697 .985} \\
& 2.790 .585 \leq 980 x_{1}+787 x_{2}+749 x_{3}+971 x_{4}+1.023 x_{5}+813 x_{6} \leq 8.488 .570 \\
& P_{2} \mu_{2}\left(f_{2}(X)\right)=\frac{1.785-\left(x_{3}+x_{5}\right)}{490} \\
& 1.295 \leq x_{3}+x_{5} \leq 1.785 \\
& P_{3} \mu_{3}\left(f_{3}(X)\right)=\frac{x_{1}+x_{2}+x_{4}-2.660}{6.076} \\
& 2,660 \leq x_{1}+x_{2}+x_{4} \leq 8,736 \\
& 0,00267 x_{6} \leq \frac{6,2}{(1-0,03)^{\frac{1}{5,8}}} \\
& 0,01 x_{1}+0,01 x_{2}+0,0144 x_{3}+0,007 x_{4}+0,0167 x_{5}+0,0067 x_{6} \leq \frac{134,5}{(1-0,1)^{\frac{1}{6,98}}} \\
& 0,0144 x_{3} \leq \frac{15,4}{(1-0,04)^{\frac{1}{6,92}}}, 0,013 x_{4} \leq \frac{35,5}{(1-0,02)^{\frac{1}{6,92}}} \\
& 0,008 x_{4} \leq \frac{21}{(1-0,01)^{\frac{1}{7}}}, 0,014 x_{6} \leq \frac{35,7}{(1-0,02)^{\frac{1}{6,90}}} \\
& 0,0245 x_{2}+0,0167 x_{5}+0,014 x_{6} \leq \frac{131,5}{(1-0,09)^{\frac{1}{7,05}}}, 0,008 x_{1}+0,04 x_{5} \leq \frac{11,9}{(1-0,08)^{\frac{1}{7,04}}} \\
& 0,01 x_{2} \leq \frac{43}{(1-0,07)^{\frac{1}{7,14}}}, 0,01 x_{3} \leq \frac{11,9}{(1-0,05)^{\frac{1}{8,45}}}, 0,005 x_{1} \leq \frac{20,4}{(1-0,06)^{\frac{1}{25}}} \\
& P_{k} \mu_{k}\left(f_{k}(X)\right)=P_{k} \mu_{k}^{*}\left(f_{k}(X)\right) \\
& P_{1} \mu_{1}\left(f_{1}(X)\right) \leq 1, P_{2} \mu_{2}\left(f_{2}(X)\right) \leq 1, P_{3} \mu_{3}\left(f_{3}(X)\right) \leq 1 \\
& P_{1} \mu_{1}\left(f_{1}(X)\right), P_{2} \mu_{2}\left(f_{2}(X)\right), P_{3} \mu_{3}\left(f_{3}(X)\right) \geq 0, x_{1}, x_{2}, x_{3}, x_{4}, x_{5}, x_{6} \geq 0 .
\end{aligned}
$$

Menggunakan software Lingo 17 diperoleh penyelesaian Permasalahan (2)

$P_{1} \mu_{1}\left(f_{1}(X)\right)=0,9999, ; P_{2} \mu_{2}\left(f_{2}(X)\right)=1,00 ; P_{3} \mu_{3}\left(f_{3}(X)\right)=0,9593$

$x_{1}=1523, x_{2}=4338, x_{3}=1075, x_{4}=2628, x_{5}=220, x_{6}=0$

Goal untuk memaksimumkan keuntungan, meminimumkan jumlah kue cepat basi dan memaksimumkan jumlah kue banyak laku dapat dicapai, hal ini dilihat dari nilai $P_{1} \mu_{1}\left(f_{1}(X)\right), P_{2} \mu_{2}\left(f_{2}(X)\right)$, dan $P_{3} \mu_{3}\left(f_{3}(X)\right)$ yang mendekati nilai 1 . Setiap minggu dapat diproduksi bolu kukus sebanyak 1523 potong, kue lapis sebanyak 4338 potong, kue pare sebanyak 1075 potong, kumbu kacang sebanyak 2628 potong, srikaya sebanyak 220 buah. 
Keuntungan yang diperoleh sebesar Rp 8.488.569, jumlah kue cepat basi sebanyak 1295 potong dan jumlah kue banyak laku sebanyak 8489.

Bentuk deterministik model PFGP berdistribusi Pareto (1) dengan prioritas Keuntungan $\left(P_{1}\right)$ dirumuskan sebagai berikut.

Maksimum

$$
D(\mu)=P_{1} \mu_{1}^{*}\left(f_{1}(X)\right)
$$

dengan kendala

$$
\begin{aligned}
& P_{1} \mu_{1}\left(f_{1}(X)\right)=\frac{980 x_{1}+787 x_{2}+749 x_{3}+971 x_{4}+1.023 x_{5}+813 x_{6}-2.790 .585}{5.697 .985} \\
& 2.790 .585 \leq 980 x_{1}+787 x_{2}+749 x_{3}+971 x_{4}+1.023 x_{5}+813 x_{6} \leq 8.488 .570 \\
& 0,00267 x_{6} \leq \frac{6,2}{(1-0,03)^{\frac{1}{5,8}}} \\
& 0,01 x_{1}+0,01 x_{2}+0,0144 x_{3}+0,007 x_{4}+0,0167 x_{5}+0,0067 x_{6} \leq \frac{134,5}{(1-0,1)^{\frac{1}{6,98}}} \\
& 0,0144 x_{3} \leq \frac{15,4}{(1-0,04)^{\frac{1}{6,92}}}, 0,013 x_{4} \leq \frac{35,5}{(1-0,02)^{\frac{1}{6,92}}} \\
& 0,008 x_{4} \leq \frac{21}{(1-0,01)^{\frac{1}{7}}}, 0,014 x_{6} \leq \frac{35,7}{(1-0,02)^{\frac{1}{6,90}}} \\
& 0,0245 x_{2}+0,0167 x_{5}+0,014 x_{6} \leq \frac{131,5}{(1-0,09)^{\frac{1}{7,05}}}, 0,008 x_{1}+0,04 x_{5} \leq \frac{48,9}{(1-0,08)^{\frac{1}{7,04}}} \\
& 0,01 x_{2} \leq \frac{43}{(1-0,07)^{\frac{1}{7,14}}}, 0,01 x_{3} \leq \frac{11,9}{(1-0,05)^{\frac{1}{8,45}}}, 0,005 x_{1} \leq \frac{20,4}{(1-0,06)^{\frac{1}{25}}} \\
& P_{1} \mu_{1}\left(f_{1}(X)\right)=P_{1} \mu_{1}^{*}\left(f_{1}(X)\right) \\
& P_{1} \mu_{1}\left(f_{1}(X)\right) \leq 1, P_{1} \mu_{1}\left(f_{1}(X)\right) \geq 0, x_{1}, x_{2}, x_{3}, x_{4}, x_{5}, x_{6} \geq 0 \text {. }
\end{aligned}
$$

diperoleh penyelesaian Permasalahan (3) sebagai berikut.

$P_{1} \mu_{1}\left(f_{1}(X)\right)=0,9999$;

$x_{1}=4090, x_{2}=111, x_{3}=0, x_{4}=2570, x_{5}=0, x_{6}=2334$

Goal memaksimumkan keuntungan dapat dicapai, hal ini dapat dilihat dari nilai $P_{1} \mu_{1}\left(f_{1}(X)\right)=0,9999$ (mendekati satu) dengan memproduksi bolu kukus sebanyak 4090 potong, kue lapis sebanyak 111 potong, kumbu kacang sebanyak 2570 potong, wajik sebanyak 2334 potong perminggu. Total keuntungan yang diperoleh sebesar Rp 8.488.569, jumlah kue cepat basi sebanyak 1295 potong dan jumlah kue banyak laku 6254 potong.

Bentuk deterministik model PFGP berdistribusi Pareto (1) prioritas meminimumkan jumlah kue cepat basi dirumuskan sebagai berikut.

Maksimum

$$
D(\mu)=P_{1} \mu_{1}^{*}\left(f_{1}(X)\right)+P_{2} \mu_{2}^{*}\left(f_{2}(X)\right)
$$

dengan kendala

$$
\begin{aligned}
& P_{1} \mu_{1}\left(f_{1}(X)\right)=\frac{980 x_{1}+787 x_{2}+749 x_{3}+971 x_{4}+1.023 x_{5}+813 x_{6}-2.790 .585}{5.697 .985} \\
& 2.790 .585 \leq 980 x_{1}+787 x_{2}+749 x_{3}+971 x_{4}+1.023 x_{5}+813 x_{6} \leq 8.488 .570
\end{aligned}
$$




$$
\begin{aligned}
& P_{2} \mu_{2}\left(f_{2}(X)\right)=\frac{1.785-\left(x_{3}+x_{5}\right)}{490} \\
& 1.295 \leq x_{3}+x_{5} \leq 1.785 \\
& 0,00267 x_{6} \leq \frac{6,2}{(1-0,03)^{\frac{1}{5,8}}} \\
& 0,01 x_{1}+0,01 x_{2}+0,0144 x_{3}+0,007 x_{4}+0,0167 x_{5}+0,0067 x_{6} \leq \frac{134,5}{(1-0,1)^{\frac{1}{6,98}}} \\
& 0,0144 x_{3} \leq \frac{15,4}{(1-0,04)^{\frac{1}{6,92}}}, 0,013 x_{4} \leq \frac{35,5}{(1-0,02)^{\frac{1}{6,92}}} \\
& 0,008 x_{4} \leq \frac{21}{(1-0,01)^{\frac{1}{7}}}, 0,014 x_{6} \leq \frac{35,7}{(1-0,02)^{\frac{1}{6,90}}} \\
& 0,0245 x_{2}+0,0167 x_{5}+0,014 x_{6} \leq \frac{131,5}{(1-0,09)^{\frac{1}{7,05}}}, 0,008 x_{1}+0,04 x_{5} \leq \frac{48,9}{(1-0,08)^{\frac{1}{7,04}}} \\
& 0,01 x_{2} \leq \frac{43}{(1-0,07)^{\frac{1}{7,14}}}, 0,01 x_{3} \leq \frac{11,9}{(1-0,05)^{\frac{1}{8,45}}}, 0,005 x_{1} \leq \frac{20,4}{(1-0,06)^{\frac{1}{25}}} \\
& P_{k} \mu_{k}\left(f_{k}(X)\right)=P_{k} \mu_{k}^{*}\left(f_{k}(X)\right) \\
& P_{1} \mu_{1}\left(f_{1}(X)\right) \leq 1, P_{2} \mu_{2}\left(f_{2}(X)\right) \leq 1, P_{1} \mu_{1}\left(f_{1}(X)\right), P_{2} \mu_{2}\left(f_{2}(X)\right) \geq 0, \\
& x_{1}, x_{2}, x_{3}, x_{4}, x_{5}, x_{6} \geq 0 .
\end{aligned}
$$

Menggunakan software Lingo 17 diperoleh penyelesaian Permasalahan (4)

$P_{1} \mu_{1}\left(f_{1}(X)\right)=1,00, ; P_{2} \mu_{2}\left(f_{2}(X)\right)=0,999$;

$x_{1}=3652, x_{2}=0, x_{3}=1075, x_{4}=2602, x_{5}=220, x_{6}=1664$.

Goal untuk meminimumkan jumlah produksi yang cepat basi tercapai, dapat dilihat dari nilai $P_{2} \mu_{2}\left(f_{2}(X)\right)$ yang mendekati 1 dengan memproduksi bolu kukus sebanyak 3652 potong, kue pare sebanyak 1075 potong, kumbu kacang sebanyak 2602 potong, srikaya sebanyak 220 potong dan wajik sebanyak 1664 potong perminggu. Total keuntungan yang diperoleh sebesar Rp 8.488.569, jumlah kue cepat basi sebanyak 1295 potong dan kue banyak laku 6254 potong.

\section{Kesimpulan}

Berdasarkan hasil dan pembahasan, dapat disimpulkan :

1. Goal memaksimumkan keuntungan dapat dicapai, hal ini dapat dilihat dari nilai $P_{1} \mu_{1}\left(f_{1}(X)\right)=0,9999$ (mendekati satu). Total keuntungan perminggu yang diperoleh sebesar Rp 8.488.569, jumlah kue cepat basi sebanyak 1295 potong dan jumlah kue banyak laku 6254 potong.

2. Goal untuk meminimumkan jumlah produksi yang cepat basi tercapai, dapat dilihat dari nilai $P_{2} \mu_{2}\left(f_{2}(X)\right)$ yang mendekati 1 . Total keuntungan yang diperoleh sebesar Rp 8.488.569, jumlah kue cepat basi sebanyak 1295 potong dan kue banyak laku 6254 potong. 
3. Goal untuk memaksimumkan keuntungan, meminimumkan jumlah kue cepat basi dan memaksimumkan jumlah kue banyak laku dapat dicapai, hal ini dilihat dari nilai $P_{1} \mu_{1}\left(f_{1}(X)\right), P_{2} \mu_{2}\left(f_{2}(X)\right)$, dan $P_{3} \mu_{3}\left(f_{3}(X)\right)$ yang mendekati nilai 1 . Keuntungan yang diperoleh sebesar Rp 8.488.569, jumlah kue cepat basi sebanyak 1295 potong dan jumlah kue banyak laku sebanyak 8489.

\section{Daftar Pustaka}

Barik, S. K. (2015). Probabilistic fuzzy goal programming problems involving pareto distribution: some additive approaches. Vol.7, 227-244.

Bolomba, A., Sahari, A., \& Jaya, A. I. (2016). Optimalisasi produksi roti dengan menggunakan metode goal programminng ( studi kasus: UKM ibaraki bakery kota palu ) Jurnal ilmiah matematika dan terapan, Vol. 12, No. 2, ISSN : 2450 - 766X, 199 - 210.

Damanik, E., Gultom, P., \& Nababan, E. S. (2013). Penerapan Metode Goal Programming untuk Mengoptimalkan Produksi Teh. Jurnal Saintia Matematika, Vol. 1, No. 2, $117-128$.

Hartini, Sahari, A., \& Ratianingsih, R. (2014). Penerapan metode goal programming untuk memaksimalkan persediaan dan meminimumkan biaya pendistribusian beras di perum bulog divre palu Jurnal ilmiah matematika dan terapan, vol.11, No.1, ISSN : $2450-766 X, 13-26$.

Kusumadewi, S., Hartati, S., Harjoko, A., \& Wardoyo, R. (2006). Fuzzy Multi-Attribute Decision Making (Fuzzy Madm). yogyakarta: Graha Ilmu.

Saifudin, T. (2006). Pendekatan Terbaik diantara Distribusi Pareto, Pareto Tergenerralisir, dan Mixture-Pareto dalam Pemodelan Reliabilitas. Jurnal Ilmu Dasar, Vol. 7, No.2, 146-154.

Siswanto. (2006). Operations Research. Yogyakarta: Penerbit Erlangga.

Tampinongkol, F. F., Rindengan, A. J., \& Latumakulita, L. A. (2015). Aplikasi Fuzzy Goal Programming (Studi Kasus: UD. Sinar Sakti Manado). Vol. 4, No. 2. 